\title{
GRAVE RELAPSE OF A LEPROMATOUS LEPROSY PATIENT TREATED FOR SIX YEARS WITH THE SULPHONE J.5I
}

\section{R. Chaussinand and N. Bourcart}

(This paper is reprinted in English translation approved by the authors, by kind permission of the Editor, La Presse Médicale. The article appeared 29 August, 1959, 40, p. 1534)

This note is about a lepromatous leprosy patient who had been presented as completely cured to the Société de Pathologie exotique in $1956^{1}$.

It concerns M. G., a former administrator in the colonies who was born in Guadeloupe in 1896 and apparently contracted leprosy in Indochina where he lived from 1924 to 1946. The diagnosis was not made until 1948 in Paris when the patient had already reached an advanced lepromatous stage. M. G. was treated with the sulphone J.51 (Diatox argentique) from 1949 to 1955, in decreasing doses of 3 tablets of $50 \mathrm{mg}$. a day for the first 2 years, to 2 tablets for the next 2 years, to 1 tablet for the last 2 years. Treatment was finally stopped in 1955 as the patient was considered completely cured.

On 20th September 1957 M.G. had a relapse. Considering himself cured, he did not say he had had leprosy and his doctor thought he was dealing with an epidermomycosis. The patient was then treated for 13 months for trophic disorders of the hands and feet of vascular origin. On 7th January 1959 M.G. had a new cutaneous evolutive reaction. Histopathological examination of biopsies taken from the hands gave the following result:

The epidermis, in localised patches lightly involved in hypertrophy of the prickle layer, was hypokeratotic and thinned out into diminishing interpapular prolongations, and separated by a thin band of the fibrous dermis from a granuloma with multi-lobular foreign bodies with histiocytes and plasmocytes. There were asteroid bodies. There was neither angiomatosis, nor any change in the capillary permeability.

There were very numerous Hansen's bacilli in the vacuoles and the histiocytes. (Z.N.)

Lepromatous leprosy of the kind which sometimes shows gigantocytes (Dr. Destombes).

M.G. was sent to us on 24th January.

In the clinical examination, we observed numerous cutaneous lepromatous lesions, purplish-blue in colour, more or less infiltrated, scattered over all the body, except for the chest, and the face appeared somewhat leonine. According to the patient, the cutaneous lesions were more considerable than those which had occurred before undergoing treatment with the sulphone J.51. There was no report 
of polyneuritic troubles. Bacteriological examinations of the skin and of the nasal mucus showed the presence of very numerous homogenous Hansen's bacilli, partially grouped in globi. The Mitsuda reaction was negative. The case presented advanced lepromatous leprosy.

M.G. was then treated with diamino-diphenylsulphone (DDS) in a moderate dosage, slowly increasing, which did not exceed the maximum dose of $2 \mathrm{mg}$. $/ \mathrm{kg}$. He reacted favourably to treatment without the least disturbance being shown.

This observation is instructive from several points of view:

It is clear first of all that many practising doctors experience great difficulties in diagnosing leprosy, and yet this infection is easy to recognise. In effect, in benign leprosy with few bacilli, certain disturbances, more or less pronounced, of the superficial sensation one always notes as far as the lesion of the skin is concerned. It is true that in the early lesions these disturbances can be minimal. However, unfortunately it is rare for patients to consult a doctor at this stage of the infection. Eventually, hypertrophy of a nervous trunk in the limbs and the local anaesthesia of neuritic origin can also facilitate the clinical diagnosis. With regard to malignant lepromatous leprosy, disturbances of the superficial skin sensation in relation to the lesions are sometimes absent and occasionally unimportant. However, bacteriological examination always reveals itself very clearly positive in the lesions of the skin. Nasal mucus also contains very numerous Hansen's bacilli, partially grouped in globi, except with certain patients whose lepromatous evolution is more or less recent.

To diagnose leprosy, it is sufficient minutely to seek out perversion, lessening or loss of sensation to touch, heat, cold, and pain with regard to skin lesions, and to take a little fragment of a lesion for bacteriological examination. At the present time, when cultural and economic ties between France and Overseas assume more and more importance it is essential that every practising doctor should be able to recognise leprosy.

Moreover, it stands out from this observation that treatment by the sulphone J.51 was clearly insufficient. That is not at all surprising since Floch, working on the levels of sulphone in the blood, showed that $200 \mathrm{mg}$. of $\mathrm{J} .51$ sulphone is about the equivalent of $50 \mathrm{mg}$. of diamino-diphenylsulphone (DDS) ${ }^{3}$. M.G. would therefore only have received the therapeutic equivalent of about $39 \mathrm{mg}$. of DDS a day for 2 years, then $26 \mathrm{mg}$. for the next 2 years, and then $13 \mathrm{mg}$. for the last 2 years. It is evident that no leprologist would dare to attempt the treatment of leprosy by administering such small doses of DDS.

The slight toxicity claimed for the sulphone J.51 is entirely due to the small quantity of DDS liberated in vivo which passes into the blood system ${ }^{4}$. To obtain a therapeutic action comparable to that 
of the sulphone $\mathrm{J} .5 \mathrm{I}$ it is sufficient to administer a dose 4 times more feeble of DDS and in that case the small toxicity of the 2 drugs is identical. Besides, treatment of leprosy by the sulphone $\mathrm{J} .51$ is much more costly than the standard treatment by DDS. There is therefore no advantage to be gained in using this derivative of DDS in the therapy of leprosy.

It is however indisputable that the state of M.G. was improved by the sulphone J.51. This shows that DDS works in very small doses and that the use of that dosage, which one of us has advocated since 1951, is perfectly justifiable ${ }^{2}$. The dosage which gives us complete satisfaction clinically and bacteriologically is the following:

We always start treatment with the oral administration daily of $25 \mathrm{mg}$. of DDS and only increase this dose very slowly, in steps of $25 \mathrm{mg}$. In practice, we only arrive gradually at the maximum dose of $2 \mathrm{mg} . / \mathrm{kg}$. after 5 months of treatment with patients with benign leprosy and only towards the 10th month with patients with the malignant lepromatous type who risk being disturbed by complications with doses too strong or progressing too rapidly.

Although with the use of weak doses of DDS increased very slowly anaemia only occurs in exceptional cases, we use tablets of $100 \mathrm{mg}$. DDS containing $200 \mathrm{mg}$. of protoxalate of iron. These tablets can be broken into 4 equal parts, giving doses of 25, 50 and $75 \mathrm{mg}$.

As the treatment of leprosy patients must be continued over several years it is recommended that the drug should be administered only 6 days out of 7 and that a week's rest should be prescribed regularly after 3 weeks of treatment to avoid an eventual accumulation of DDS in the body. These halts of short duration should not cause any inconvenience.

The oral administration of DDS daily according to the dosage given above is without any doubt the best treatment for leprosy, probably because it causes blood sulphone levels relatively weak, yet steady and constant enough.

Many leprologists still actually use DDS in doses too strong and progressing too rapidly. This increased dosage not only does not bring any more spectacular improvement than the one we advise but on the contrary brings about the frequent occurrence of complications, more or less serious (anaemia, reaction).

Certain authors fear that the treatment by DDS in small doses progressing slowly could bring about a resistance to sulphone in the Hansen's bacillus. This fear has no foundation, since from 1948 no characteristic case of resistance to sulphones can be found among the hundreds of thousands of patients who undergo, more or less regularly, treatment by DDS. On this subject also the observation of M.G. is of great interest. In effect, this patient followed a sulphone treatment for 6 years, actually equivalent to small and decreasing 
doses of DDS (39 mg. to $13 \mathrm{mg}$. a day). In spite of this dosage, which should have induced the occurrence of resistance to sulphones, the introduction of a new treatment by weak doses of DDS still produced in a short time a remarkable improvement in the cutaneous lesions caused by a serious lepromatous relapse.

\section{References}

1. BASSET, A. Resultats eloignés du traitement de la lèpre par la sulfone J.51. Bull. Soc. Path. Exotique, 1956, 49, 593.

2. Chaussinand, R. Thérapeutique de la lèpre. Rev. Practicien, 1954, 21, 1955 ; Condense de leprologie à l'usage du médecin praticien. Sem. Hop. Paris, 154, 79, 4405; La Lèpre, 2nd edit., Expansion Scientifique Française, edit., Paris.

3. FlOCH, H. and Gelard, A. M. La sulfone J.51 en thérapeutique antilepreuse. Bull. Soc. Path. exotique, 1955, 48, 133.

4. Rist, N., Boyer, F., Saviard, M. and Hamon, V. Sur le mode daction d'une sulfone thymolée argentique. Rev. Tuberc., 1954, 18, 1407. 